DOI 10.1515/linpo-2017-0002

\title{
On reductionism in communication studies
}

\author{
Jarosław Boruszewski \\ Institute of Philosophy, Adam Mickiewicz University in Poznań \\ borjar@amu.edu.pl
}

\begin{abstract}
Jarosław Boruszewski. On reductionism in communication studies. The Poznan Society for the Advancement of the Arts and Sciences, PL ISSN 0079-4740, pp. 15-25

In contemporary philosophy of communication we have two competing views on communication. In short they are called message-centred and meaning-centred. The first one is described as reductionist because it reduces communication to transmission of information. In the article a distinction has been made between a purely transmissional approach, which does not have a reductionist character and the reductionist account, which in an unjustified manner, conflates the transmission problem with semantic issues. For this purpose, the concept of levels of analysis and considerations concerning a conduit metaphor were used. Given the limited application of the reductionist approach in communication studies, in the last section of the article an integration approach is proposed. Such an approach, while avoiding conflation of levels, allows for their combining and finding connections between them.
\end{abstract}

Keywords: communication studies, reductionism, levels of analysis, transmissonal approach, conduit metaphor

\section{Communication and reduction}

Undoubtedly, the problem of reductionism is one of the most frequently tackled matters in contemporary philosophy and methodology of science. The scope of issues raised within this problem covers general philosophical considerations on reductionism, the reduction between particular scientific disciplines and the reduction of all sciences to one basic discipline. It also covers the question of reductionism in a given field of knowledge, which is the subject matter of this article referring in particular to the problem of reductionism in communication studies. It is important to say that although this issue has been developed for a long time, it has only happened recently that it has been tackled directly in reference to reductionism. In order to make a good introduction, I would like to quote some representative statements from the latest literature on the subject matter:

Everyday references to communication are based on a "transmission" model in which a sender transmits a message to a receiver - a formula which reduces meaning to explicit "content" which resides within the text and is delivered like a parcel (Chandler 2007: 178-179). 
Issue causing disputes over the transmission models is the reduction of communication activities for the transfer of information (Wendland 2013: 52).

Communication scholars historically took the path of least resistance, the reductionist strategy of identifying pragmatics with behaviour, conceiving messages as containers of information that are more or less tactically successful in production, delivery and exchange (Catt 2015: 346).

My aim is to highlight the common and harmful confusion between relative information and content or meaning. This confusion lies at the heart of reductionism [...] since the reductionist program is founded on the hope of reducing all contents to information, by means of formal systems, on the way to their ultimate reduction to absolute information (Bar-Am 2016: 94).

Although these statements differ, it is easy to make a list of some key words: "reduction", "communication", "transmission", "information", "message", "meaning". These key words or, strictly speaking, concepts that they express, define the spectrum of issues of this paper.

As it can be easily seen, the problem of reductionism in communication studies refers to a very basic question - what is communication or how to understand the term "communication"? In the Introduction to Communication Studies John Fiske adopts a general definition of communication understood as a social interaction through messages. He also claims that there are two main approaches. The first one perceives communication as a transmission of messages, whereas the other sees it as a production and exchange of meanings (Fiske 1990: 2). This difference is crucially related to the problem of reductionism and can be expressed in other way as a controversy between two perspectives in the philosophy of communication: message-centred and meaning-centred (Barnlund 1962: 198-201). Before I bring up the main subject, I would like to present shortly the philosophical characteristics of reductionism.

Generally speaking, reductionism can be defined as a philosophical attitude characterised by an expression "nothing but" (e.g., gene is nothing but a string of nucleic acid bases) (Rosenberg 2001: 135). In this sense, complex systems or phenomena can be explained in terms of principles governing their constituents. We deal then with phenomena or processes from higher (secondary) levels or the ones from lower and more basic levels. These levels differ with respect to their complexity, up to the ultimate level, to which all other levels can be reduced. They can also be understood ontologically or epistemologically. To be more precise, they are compositional levels of organization or levels of description or analysis. Conflation of these is a frequent mistake present in philosophical considerations particularly in the ones referring to reductionism (Wimsatt 2007: 201; Nagel 1998: 10). Since I am dealing with communication studies, the ontological questions will not appear in this article. However, the concept of the level of analysis will be relevant in my considerations. Conversely, the anti-reductionist attitude can be characterised by a phrase "more is different" (Anderson 1972). In this attitude, higher levels cannot be (fully) reduced to lower levels on account of their own specifics. 


\section{The levels of analysis}

The background of the problem of reductionism in communication studies is the application of Claude Shannon's mathematical theory of communication to describe everyday communication between humans. This theory which originates from the studies in cryptography was developed for engineering purposes. It is important to say that the problem of reductionism does not emerge on the grounds of Shannon's theory. It was as if to say generated in the first informal version of this theory introduced by Warren Weaver. Let us then proceed to the discussion and interpretation of this version from the perspective of reductionism.

The following three levels of problems in the studies of communication are the basis:

(A) Technical level - How accurately can the symbols of communication be transmitted?

(B) Sematic level - How precisely do the transmitted symbols convey the desired meaning?

(C) Effectiveness level - How effectively does the received meaning affect conduct in the desired way?

It is well known that Shannon made a clear distinction between these levels, but he only dealt with level A. However, Weaver admitted that separation into the levels is artificial and undesirable (Weaver 1949: 25). In the remaining discussion, I will only refer to levels $\mathrm{A}$ and $\mathrm{B}$ because the question of relation between them is relevant to the problem of reductionism. Shannon described this relation in the following way:

"Information" here, although related to the everyday meaning of the word, should not be confused with it. In everyday usage, information usually implies something about the semantic content of a message. For the purposes of communication theory, the "meaning" of a message is generally irrelevant; what is significant is the difficulty in transmitting the message from one point to another (Shannon 1993: 173, emphasis mine).

The meaning of a message is irrelevant for its transmission. Weaver addressed Shannon's claim in the following way: "this does not mean that the engineering aspects are necessarily irrelevant to the semantic aspects" (Weaver 1949: 8). Such a statement clearly suggests that the technical level is basic, whereas the semantic one is secondary. Therefore, one can say that the first step towards reductionism has been made - a distinction between basic and secondary levels.

The indication of level A as basic can be justified by the fact that it is considered to be syntactic (Cherry 1966: 244). The conclusion that level B (semantic) is irrelevant to level A (syntactic) and not the other way round can be drawn automatically. However, this view is contested. Transmission is a necessary condition of the emission and perception of information, whereas syntactics is necessary for its interpretation. When it comes to syntax, we deal with internal relations in a given language and syntactic constraints set upon this language. On the level of transmission, we encounter a totality of statistical 
constraints placed upon an ensemble of signals which define potential meanings of sent messages (Nauta 1972: 39, 58). Moreover, according to Weaver's characteristics, we do not deal with organisational levels but with the levels of analysis. While the stratification of levels is present in the former, the same cannot be said about the latter: "reference to levels need not imply a hierarchy or ranking of importance. [...] Research at one level is not inherently superior to research at the other level" (MacDougall-Shackleton 2011: 2077). Having considered that, Shannon's claim can be understood in the way that semantic problems are generally irrelevant from a technical perspective and, conversely, that technical problems are generally irrelevant from a semantic perspective. Umberto Eco noticed the following: "semiotics is not concerned with electrical laws, nor with the electronic "stuff" which allows us to "make" electric signals; it is only interested in the selected signals insofar as they convey some content" (Eco 1976: 51, emphasis mine). Thus, the stratification of levels is not an obvious issue. However, even if we accept stratification, it only makes reduction possible and is not its realisation yet. The key to this realisation is outlined by Eco and can be defined as the problem of conveying.

\section{The problem of conveying}

The problem of conveying is the key to diagnose reductionism in a transmissional view. It can be defined as a simple question - what is de facto transmitted? As Weaver states in his characteristics of level B: How precisely do the transmitted symbols convey the desired meaning? Is the meaning also transmitted apart from the message? John Fiske provided the following solution: "Shannon and Weaver consider that the meaning is contained in the message: thus improving the encoding will increase the semantic accuracy" (Fiske 1990: 7, emphasis mine). At this point, it is necessary to separate Shannon's original theory from Weaver's version. In Shannon's theory, there is no such thing as conveying a meaning, but Weaver claimed the opposite. Michael Reddy addressed this issue in his famous article about a conduit metaphor. An essential ingredient of this metaphor is that language functions like a conduit and words, containing thoughts, convey them from one person to the others (Reddy 1993: 170). It is a naïve view of communication, where senders put meanings into words and receivers extract these meanings. To be precise, conduit metaphor is not present in Shannon's original theory. Firstly, in this theory we do not even deal with meaning. Secondly, there is no "putting" something into something else. There is only coding and decoding - mapping or correspondence between one set of signs and the other. One can only say that a sequence of signals represents a message, and representing is something completely different from containing. Reddy is obviously right in accusing Weaver of conduit metaphorisms, but his accusations do not target Shannon's original theory. In this sense, a pure transmissional view radically departs from conduit metaphor "by not rendering meanings as residing in what is transmitted" (Krippendorf 2009: 58, emphasis original). In the strict sense, the meaning is not transmitted or contained in any way in transmission and can be even described as non-transmittable. But if we want to understand communication as transmission, we can 
come to a conclusion that the meaning is essentially incommunicable (Husson 1994: 54). The meaning then can neither be emitted, transmitted nor received.

One should therefore ask if the meaning is not transmitted, then what is? This issue was also addressed by Reddy, who criticized the view that what is transmitted is a message. He observed that the term "message" is ambiguous:

The "messages" are not contained in the signals. [...] They carry no little replica of the message. [...] MESSAGE Means literally a set of signals, whereas MESSAGE $_{2}$, means the repertoire members involved with the communication. For conduit-metaphor thinking, in which we send and receive the MESSAGE , within the MESSAGE , the ambiguity is trivial. But for a theory based totally on the notion that the "message" (MESSAGE $\left.{ }_{2}\right)$ is never sent anywhere, this choice of words leads to the collapse of the paradigm (Reddy 1993: 182-183).

Reddy is undoubtedly right in saying that the term "message" is ambiguous, but he does not notice the same feature about the term "transmission". Let us consider Shannon's communication model: information-source - transmitter - receiver - destination. There is a selected message from the source and a reconstructed message at the point of destination, as well as a flow of signals from transmitter to receiver. On the one hand, the term "transmission" is understood literally and non-metaphorically, as transmission sensu stricto - flow of signals. On the other hand, transmission has a metaphorical character and this understanding of this term is a basis for conceptualising communication in a transmissional approach. We then reason in such a way that if what is communicated is a message, and communicating is conceptualised by a metaphor of transmission, then this stands as an example of a transmission of a message. This matter can also be expressed in such a way that communication is transmission. If you remember about this ambiguity, understanding should not be problematic. We can then quote after Shannon about the philosophical and operational aspect of the mathematical theory of communication:

On the philosophical level, one is able to understand the communication process and measure what is being sent, measure information in so many bits or choices per second. On the actual operational level, it enables you to combat noise and send information efficiently and use the right amount of redundancy to allow you to decode at the receiving end in spite of noisy communication (Liversidge 1993: xxvii).

If you adopt such a view, it becomes clear that the transmission model is message-centred, and not just signal-centred. However, it is necessary to remember not to conceptualise the message within the conduit metaphor. Strictly speaking, there is no message flow from one point to another. There is a selection and a reconstruction of a message. However, this matter requires further comments. In Shannon's view, reproduction of message is a fundamental problem in communication (Shannon 1949: 31). This statement has been followed by a number of contradictory interpretations. On the one hand, it is strongly connected with the conduit metaphor: "this statement [...] became the mantra of all communication theorists in search of ways to ensure that communication successfully transmits the meaning the sender has in mind to the receiver seeking to understand this meaning" (Baecker 2013: 87, emphasis mine). An opposite interpretation was adopted by, e.g., Klaus Krippendorff, who clearly distinguishes reproduction from transmission and 
also considers the use of conduit metaphor as a misconception (Krippendorff 2009: 616618 ).

At this point, it is necessary to ask a question concerning the relation between conduit metaphor and reductionism. The fact that Shannon left the issue of meaning aside allowed him to formulate a precise theory, and, above all, the measure of the quantity of information. However, Weaver thought that if he had brought up the meaning, he would have been able to combine the precision of a mathematical theory with the common view of communication. Willingly or not, he took the conduit metaphor into consideration. In fact, Weaver in a way "stuffed" the message with the meaning. Then it is enough to deal with formal issues, which in turn will lead to semantics being "forced into" the system. In such a way, the theory might keep its operational value and at the same time cover the common view. In doing so, one more or less directly apply the theory to common communication activities. This is definitely a reductionist attitude. Level A is basic if the meanings from level B are "implemented" into the messages from level A, and the formalism of the theory from the level A will do the rest. In this way nothing or at least very little will remain specific for level B. Weaver's way of complementing the communication scheme can prove this thesis. He introduced two additional semantic elements - semantic receiver and semantic noise. Moreover, in Weaver's opinion, an introduction of the elements form level B to level A was not a serious methodological manoeuvre: "It is almost certainly true that a consideration of communication on levels $\mathrm{B}$ and $\mathrm{C}$ will require additions to the schematic diagram [...], but it seems equally likely that what is required are minor additions, and no real revision" (Weaver 1949: 26, emphasis mine).

The above explanation can be commented as "more is not different", and an introduction of semantic elements to an originally asemantic theory does not violate the rule "nothing but": communication is nothing but transmission of messages. Nimrod Bar-Am, a contemporary philosopher of communication, characterised Weaver's manipulation in the communication scheme as typically reductionist: "to treat distinct levels of description as if they are virtually identical [...]. Conflation of different levels of description that is so typical of the reductionist" (Bar-Am 2016: 124, 136, emphasis mine).

Let us ask then about the source of such specific reductionism. Strictly speaking, the source is in forgetting about the bracketing of meaning. Shannon in a way isolated the message (level A) by suspending semantic issues. If we are aware of such a manoeuvre, then there is no risk of encountering either a conduit metaphor or conflation of levels. However, there would still be a certain tempting possibility: "models of communication have been designed to analytically and operationally isolate the "message" so that it may be studied as a self-contained event" (Thomas 1980: 433, emphasis mine). At this point, we should pay attention to two aspects that have emerged. An operational aspect is an engineering point of view. In this respect, it is important to send a given sequence of signals (representing a significant message) in the most economical and effective way. The engineer does not have to remember about suspending meaning in order to transmit a particular "isolated" message. In this sense, it is possible to say that the meaning is then taken for granted (Nauta 1972: 176). In the analytical sense, the situation is different because the meaning cannot then be taken for granted. John Deacon described such a situation in a very precise and suggestive way: 
aboutness and [...] significance are assumed potentialities but are temporarily ignored. The danger of being inexplicit about this bracketing of interpretive context is that one can treat the sign as though it is intrinsically significant, irrespective of anything else, and thus end up reducing intentionality to mere physics, or else imagine that physical distinctions are intrinsically informational rather than informational only post hoc, that is, when interpreted (Deacon 2010: 134).

This matter seems to be quite simple. However, there is still something intriguing and catchy in this simplicity. The suspension of a "semantic superstructure" makes operationalization of a "clear" message possible. But the lack of awareness of this suspension in connection with the effectiveness of transmission generates an image of something internally meaningful which is somehow sent via communication channel. Inexplicit bracketing of meaning, though it sounds somewhat enigmatic, is probably a deep source of reductionism in thinking about communication. One can also assume that it is a kind of a form of magical thinking - transformation of physical signals onto meaningful messages. According to the philosophical accounts of magic, in a magical way of thinking causal connection transforms itself into symbolizing relation and the reverse (Kmita 1996: 591). We can therefore say that the conduit metaphor is a relic of magical thinking about communication.

\section{Universality of transmissional approach}

Weaver's postulate was to formulate a "general theory at all levels" (Weaver 1949: 27). It was supposed to be a kind of unification. However, it is obvious that this unification is reductionist. Weaver thought that mathematical theory of communication is a fundamental theory with a basic level of generality (Weaver 1955: 21). Therefore, it is a theory which unifies all problems referring to communication. Moreover, according to Weaver, this theory in itself uncovers crucial semantic and pragmatic problems: "analysis at Level A discloses that this level overlaps the other levels more than one could possi-

ble naively suspect. Thus the theory of Level A is, at least to a significant degree, also a theory of levels B and C" (Weaver 1949: 6). Therefore, this theory is comprehensive. However, an ambiguity referring to the concept of generality emerges at this point. As far as Shannon's theory as a mathematical one can be considered general, it cannot be at the same time a theory of meaning because it then refers to transmission in an operational aspect. In this sense, every communicative action is connected with an emission of signals in a physical sense. However, this claim is banal. But Weaver's three-level theory cannot be general because it is involved with the conduit metaphor in such a way that it is limited to conventional communicative activities restrained only to the selection of available meanings. Communicative activities that are based on a broadly understood creation of meaning remain beyond reach for this theory. Therefore, an attempt to transfer the universality of communication theory to the whole model of communication makes this model limited in its application. In this case, reduction is not successful and the rule "more is different" comes to the foreground. This reduction, being an attempt to make transmission universal to all communicative actions, is also an expression of ahistorical 
understanding of the concept of communication - every communicative action (always and anywhere) falls into a transmission model (Wendland 2013: 55-56). This ahistoricity is also visible in the fact that no attention is paid to the cultural context in which the transmission model was created. The mathematical communication theory was formed on the basis of studies in advanced cryptography. The projection of such a model of communication onto communicative actions coming from, for example, distant past or cultures which are technologically less developed would be an unjustified theoretical imputation.

As far as the universality of the mathematical communication theory is concerned, we should also pay attention to two things: "the transmissional approach represents the most general approach to information in that it abstracts from the concrete semiotic situation and reduces communication to its most elementary aspects" (Nauta 1972: 193). These qualities were definitely paramount to ensure the success of Shannon's theory. It has stood the test of time and has remained valid and inspiring. The first quality - an abstraction from the concrete semiotic situations - makes the theory metalanguage-based in character. It is a description of the communication process from the point of view of outer observer who does not participate in the communicative activities that he or she observes. The outer observer does not use an object-language which is used by the interlocutors to communicate (Cherry 1966: 92, 172). From this perspective, you can have access only to observable, transmitted messages and the reactions to them. The meaning of the messages remains unavailable for the observer. Once again, in this respect - though the context might be different - the asemantics of the mathematical communication theory decisive about its own generality emerges. Another aspect is the reduction of communication to its elementary aspects. This reduction made the theory popular on account of its simplicity. The only thing that Shannon's followers did was broadening or completing the original model. In this respect, it is advisable to consider and not to exclude the creation of a new communication theory which will present the even more basic elements of the process of communication. Therefore, once again, it appears that one should not disregard the cultural context of the time when the mathematical communication theory was created.

\section{Reduction or integration?}

The question of the priority of concepts used in conceptualising communication is a point of dispute between the reductionist and non-reductionist views. Which is prior to which - message or meaning? If the message is prior, then it is a vehicle of meaning or its generating tool. Alternatively, the meaning is the result of the message being sent. If the meaning is prior, then the meaning is prerequisite to recognition of a message as such (Catt 2013: 105; Catt 2014: 203). But the question remains whether it is necessary for either of the two options to be chosen. Perhaps it is best to follow Peter Strawson's advice and instead of choosing the either-or option, one should adopt a "model of tracing connections $[\ldots]$ without hope of being able to dismantle or reduce the concepts we examine" (Strawson 1992: 21). In the context of the problem of reductionism, Strawson's advice becomes very useful if we - as it happens in communication studies - refer to 
the concept of the levels of analysis. This concept proved to be very useful in, for example, studies of animal behavior, where instead of competition between different schools of thinking (e.g., nature-nurture controversy), four complementary levels of analysis have been distinguished: evolutionary, functional, ontogenetic and mechanistic (Sherman 1988: 616-617). With such levels of analysis at disposal, if one abandons all reductionist claims, then such an attitude can be heuristically fruitful. Therefore, in the end of my article, I would like to present an outline of an approach which integrates message-centred and meaning-centred perspectives.

First, one should be aware of the cognitive risk that is connected with integration. The levels of analysis must not be mistaken or tangled. The postulated differences must still be maintained. Conflation of levels is not allowed but this does not mean that considerations on different levels cannot be combined and finding connections between them is not plausible. In a sense, this requires an analytical agility to be able to move between the levels and to know how epistemic perspectives change when this happens. The integration requires clear methodological consciousness of the levels of analysis:

Integrating across levels of analysis is tricky business. [...] Integration across levels of analysis $[\ldots]$ requires detailed knowledge of other research domains, and is thus often best conducted via collaborations. [...] Although there is risk of confusion, careful consideration of one level of analysis can benefit research at the other (MacDougall-Shackleton 2011: 2083).

An integrative attitude is a kind of remedy to universalist and reductionist claims. However, integration should not be perceived in a naïve way. Statements on different levels referring to similar problems may not compete with one another. However, there are situations with exclusive alternatives, from which at least one can be sound (Mitchel \& Dietrich 2006: S76-S77). If an integrative attitude turns out to be effective in explanation of signal behavior of animals, why not suppose that it might also be useful in the study of human communicative activities?

The reductionist attitude in communication studies encounters numerous obstacles, and reductive models have a limited scope of application. This makes message-centred philosophy a very restricted view of communication and meaning-perspective cannot be disregarded. However, this does not mean that basic terms from transmissional view have no heuristic power. Let us at least consider a very interesting use of the concept of noise to describe subversive communication (Schweighauser 2014: 32-37). To sum up, I would like to bring up a certain idea from the beginning of 1980s. This idea is still valid and would require an integration of two perspectives in communication philosophy to be fully tackled. The idea is called the lag-of-meaning-behind-information:

Information accumulating at an exponential rate is outstripping meaning formation [...]. The reasons for the lag in meaning formation [...] seem to be: inherent slowness of meaning formation [...] and information becoming noiselike [...]. To test empirically such hypotheses requires appropriately measuring and comparing rates and kinds of meaning formation with rates of other sorts of information processing, and of noise production" (Klapp 1982: 64).

In order to study the problems highlighted in the hypothesis above fully, an integration of a perspective oriented on the transmission of messages and a perspective concerned 
with the production of meanings would be necessary. This is indeed the case because this hypothesis involves the cultural discrepancy between these processes. It would not be enough to study this problem from only one perspective and would also be undoubtedly biased. However, this problem is here only signaled as it is already a subject of a separate study.

\section{References}

Anderson, Philip W. 1972. More Is Different. Science 177. 393-396.

Baecker, Dirk. 2013. Systemic theories of communication. In Cobley, Paul \& Schulz, Peter J. (eds.), Theories and Models of Communication, 85-100. Berlin: De Gruyter.

Bar-Am, Nimrod. 2016. In Search of a Simple Introduction to Communication. Dordrecht: Springer.

Barnlund, Dean C. 1962. Toward a Meaning-centred Philosophy of Communication. Journal of Communication 12. $197-211$.

Catt, Isaac E. 2013. Culture in the Conscious Experience of Communication. Listening. Journal of Communication, Ethics, Religion, and Culture 2. 99-119.

Catt, Isaac E. 2014. The Two Sciences of Communication in Philosophical Context. The Review of Communication 14. 201-228.

Chandler, Daniel. 2007. Semiotics. The Basics. London, New York: Routlege.

Cherry, Colin. 1966. On Human Communication: A Review, a Survey, and a Criticism. Cambridge, London: The Massachusetts Institute of Technology Press.

Deacon, Terence W. 2010. What is missing from theories of information? In Davies, P.C.W. \& Gregersen, Niels Henrik (eds.), Information and the Nature of Reality: From Physics to Metaphysics, 123-142. Cambridge: Cambridge University Press.

Eco, Umberto. 1976. A Theory of Semiotics. Bloomington, London: Indiana University Press.

Fiske, John. 1990. Introduction to Communication Studies. London, New York: Routledge.

Husson, William. 1994. A Wittgensteinian critique of the encoding-decoding model of communication. Semiotica 98. 49-72.

Klapp, Orin E. 1982. Meaning Lag in the Information Society. Journal of Communication 32. 56-66.

Kmita, Jerzy. 1996. Towards Cultural Relativism "with a Small 'R'". In Zeidler-Janiszewska, Anna (ed.), Epistemology and History. Humanities as a Philosophical Problem and Jerzy Kmita's Approach to it, 541-614. Amsterdam, Atlanta: Rodopi.

Krippendorf, Klaus. 2009. On Communicating. Otherness, Meaning, and Information. London, New York: Routledge.

Liversidge, Anthony. 1993. Profile of Claude Shannon. In Shannon, Claude E., Collected Papers, xix-xxxiii. New York: John Wiley \& Sons.

MacDougall-Shackleton, Scott A. 2011. The levels of analysis revisited. Philosophical Transactions of The Royal Society B 366. 2076-2085.

Mitchell, Sandra D. \& Dietrich, Michael. 2006. Integration without Unification: An Argument for Pluralism in the Biological Sciences. The American Naturalist 168. S73-S79.

Nagel, Thomas. 1998. Reductionism and Antireductionism. In Novartis Foundation, The Limits of Reductionism in Biology, 3-14. New York: John Wiley \& Sons.

Nauta, Doede Jr. 1972. The Meaning of Information. Hague, Paris: Mouton.

Reddy, Michael J. 1993. The conduit metaphor: A case of frame conflict in our language about language. In Ortony, Andrew (ed.), Metaphor and Thought, 164-201. Cambridge: Cambridge University Press.

Rosenberg, Alex. 2001. Reductionism in a Historical Science. Philosophy of Science 68. 135-163.

Schweighauser, Philipp. 2014. The persistence of information theory. In Arnold, Darrell P. (ed.), Traditions of Systems Theory: Major Figures and Contemporary Developments, 21-44. New York: Routledge.

Shannon, Claude E. 1949. The Mathematical Theory of Communication. In Shannon, Claude E. \& Weaver, Warren, The Mathematical Theory of Communication, 29-125. Urbana: The University of Illinois Press. 
Shannon, Claude E. 1993. Communication Theory - Exposition of Fundamentals. In Shannon, Claude E., Collected Papers, 173-176. New York: John Wiley \& Sons.

Sherman, Paul W. 1988. The Levels of Analysis. Animal Behaviour 36. 616-619.

Strawson, Peter F. 1992. Analysis and Metaphysics. An Introduction to Philosophy. Oxford: Oxford University Press.

Thomas, Sari. 1980. Some Problems of the Paradigm in Communication Theory. Philosophy of the Social Sciences 10. 427-444.

Weaver, Warren. 1949. Recent Contribution to the Mathematical Theory of Communication. In Shannon, Claude E. \& Weaver, Warren, The Mathematical Theory of Communication, 1-28. Urbana: The University of Illinois Press.

Weaver, Warren. 1955. Translation. In Locke, William N. \& Booth, A. Donald (eds.), Machine translation of languages: fourteen essays, 15-23. New York: John Wiley \& Sons.

Wendland, Michał. 2013. Controversy Over the Status of the Communication Transmission Models. Dialogue and Universalism 1. 51-63.

Wimsatt, William C. 2007. Re-Engineering Philosophy for Limited Beings. Piecewise Approximations to Reality. Cambridge, London: Harvard University Press. 